GARY KING and CHRISTOPHER J. L. MURRAY note that many attempts to ensure the territorial security of nation-states through military power have failed to improve their total human condition. In response, the international community has moved to combine economic development with military security and other basic human rights to form a new concept of "human security." Unfortunately, by common assent the concept lacks either a clear definition or any agreed upon measure of it. 


\section{Rethinking Human Security}

\section{GARY KING \\ CHRISTOPHER J. L. MURRAY}

In the $1990 \mathrm{~s}$, the two dominant strands of foreign policy-economic development and military security-became intertwined. The development and security establishments have also each undergone a period of conceptual turmoil with the end of the cold war, the recognition of highly uneven patterns of change in different components of development, and the technological and political changes often labeled globalization. One consequence has been the emergence of the concept of human security. As fostered by the United Nations Development Program, this term usually means "freedom from fear and want."1 Human security has rapidly moved to occupy center stage in discussions of foreign policy; for example, the Group of Eight (G8) foreign ministers declared in June of 1999 that they are "determined to fight the underlying causes of multiple threats to human security...." Despite articulated links to both the development and security fields, alternative definitions abound for human security, and the research and policy agenda for human security remains unclear.

In this article, we propose a simple, rigorous, and measurable definition of human security: the number of years of future life spent outside a state of "generalized poverty." Generalized poverty occurs when an individual falls below the threshold of any key domain of human well-being. An agenda for research

\footnotetext{
${ }^{1}$ Lincoln C. Chen, "Human Security: Concepts and Approaches" in T, Matsumae and L.C. Chen, eds., Common Security in Asia: New Concepts of Human Security (Tokyo: Tokai University Press, 1995); United Nations Development Program (UNDP), New Dimensions of Human Security (New York: Oxford University Press, 1994); A. Florini and P. J. Simmons, The New Security Thinking: A Review of the North American Literature (New York: Carnegie Endowment for International Peace, 1998).

${ }^{2}$ Lloyd Axworthy, "An Address On Human Security," Minister Of Foreign Affairs, To The G-8 Foreign Ministers' Meeting, 9 June 1999.
}

GARY KING is professor of government and director of the Harvard-MIT Data Center at Harvard University, and senior science adviser at the World Health Organization.

CHRISTOPHER J. L. MURRAY is executive director of the Evidence and Information for Policy Cluster at the World Health Organization. His work has focused on measuring health and health system performance in nations around the world. 
and action to enhance human security follows logically from this definition in the areas of risk assessment, prevention, protection, and compensation. We propose that the academic and policy communities develop the forecasting methods and databases so that routine measurement of the average level of human security in different communities can be undertaken. We begin with some of the antecedent developments in the areas of development economics and national security that led to the emergence of the concept of human security. We conclude with a discussion of some areas of research and action to enhance human security that have been neglected and the need for closer interaction between different disciplines addressing human security, such as political science and public health.

\section{From National Security to Human Security}

\section{The Development of Development Economics}

As early as when William Petty and Adam Smith wrote in the seventeenth and eighteenth centuries, the field of development economics has focused on broad, inclusive definitions and goals for human achievement and well-being. ${ }^{3}$ However, following World War II, politicians and practitioners in international and bilateral aid agencies, together with the academic community and nongovernmental organizations (NGOs), turned their focus to national income as the main object of development. This change was coincident with the widespread application of national income and product accounts to measure economic activity, ${ }^{4}$ the creation of the World Bank and the International Monetary Fund, and the widespread perception that human well-being was advanced primarily through economic growth.

Gradually, this narrowed focus on per capita income became the subject of criticism as writers pointed out the stark comparison with the earlier, more inclusive approach. ${ }^{5}$ Dissatisfaction with improvements in the circumstances of the most impoverished nations and the plight of the poorest in all nations spawned the basic needs movement in the 1970 s, which emphasized achievement of a minimum standard for all as the first priority. ${ }^{6}$ In the 1980 s, nations such as Sri Lanka, Cuba, China, Costa Rica, and the Kerala State in India--with

\footnotetext{
${ }^{3}$ Sir William Petty, Political Arithmetick (London: Robert Clavel and Hen. Mortlock, 1690); Adam Smith, An Inquiry into the Nature and Causes of the Wealth of Nations, 1776, (rcpublished Oxford, UK: Clarendon Press, 1976).

${ }^{4}$ Robert Eisner, The Total Incomes System of Accounts (Chicago: University of Chicago Press, 1989).

${ }^{5}$ Mahbub Ul-Haq, Reflections on Human Development (Oxford, UK: Oxford University Press, 1995); Amartya K. Sen, "Development Thinking at the Beginning of the $21^{\text {st }}$ Century" in Louis Emmerij, ed., Economic and Social Development into the XXI Century, (Washington, DC: Inter-American Development Bank distributed by Johns Hopkins University Press, 1997).

${ }^{6}$ Stephen Knowles, "The Evolution of Basic Needs and Human Development," Revista Internationale di Scienze Economichice e Commerciall 60 (1993): 513-42.
} 
long life expectancies at birth and low levels of income per capita ${ }^{7}$-heightened the recognition that income does not always predict other components of wellbeing. UNICEF's efforts to study the impact of structural adjustment on the health, nutrition, and education of children were particularly influential in this regard. ${ }^{8}$ Capturing these concerns, Mahbub ul-Haq launched the United Nations' Human Development Report in $1990 .^{9}$ In its report, the United Nations Development Program (UNDP) argued that development must be focused on people (even though grouped by country) rather than the security of their na" tional boundaries, and on advancing health, education, and political freedom in addition to economic well-being. Development was defined broadly as expanding people's choices in almost any relevant way. To enhance dialogue on human development and garner increased political attention, the UNDP now publishes annually the "Human Development Index," which is a somewhat narrower, but still broad composite measure of income per capita, life expectancy at birth, and educational attainment. ${ }^{10}$ The general view, that development is not merely income, is linked in the Human Development Report to Amartya Sen's theory of capabilities. ${ }^{11}$ Sen's most recent formulation attempts to justify the movement in terms of expanding individuals' freedoms. ${ }^{12}$

The human development perspective has remained controversial, ${ }^{13}$ but it has been widely influential in emphasizing nonincome dimensions of human well-being in the development policy debate. In some ways, the increasing focus of the World Bank and the International Monetary Fund on poverty alleviation, rather than their previous goal of increasing growth, can be seen as a response to the UNDP emphasis on human development. For another example, the UK Department for Foreign and International Development (DFID) has taken a similar approach and announced that its strategy is to reduce poverty by half in $2015 . .^{14}$

\section{The Changing Nature of Security}

In parallel to the debate over development, a different set of national and international actors, organizations, and academics has been debating the meaning

${ }^{7}$ Scott B. Halstead, Julia A. Watsh, Kenneth S. Warren, cds., Good Health at Low Cost (New York: Rockefeller Foundation, 1985).

${ }^{8}$ Richard Jolly, Andrea Giovanni, Frances Stewart, eds., Adjustment with a Human Face: Protecting the Vulnerable and Promoting Growth (New York: Oxford University Press, 1988).

${ }^{9}$ UNDP 1990.

${ }^{10}$ Ul-Haq, Reflections.

${ }^{11}$ Amartya K. Sen, Inequality Reexamined (Cambridge, MA: Harvard University Press, 1992).

${ }^{12}$ Amartya K. Sen, Development as Freedom (New York: Knopf, 1999).

${ }^{13}$ Martin Ravaillon, "Good and Bad Growth: The Human Development Reports," World Development 25 (1997): 631-8; Harsha Aturupane, Paul Glewwe, and Paul Isenman, "Poverty, Human Development and Growth: An Emerging Consensus?" American Economic Review, Papers and Proceedings 84 (May 1994): 244-9.

14 Clare Short, secretary of state for International Development, UK Government. 
of security. The traditional view of security has focused on using the military to ensure the territorial integrity of sovereign states. Security studies and the security establishment have long been focused on foreign and defense policy mechanisms to avoid, prevent, and if need be win interstate military disputes. ${ }^{15}$

The funds spent on military security have been as large globally as the combined income from 49 percent of the world's people..$^{16}$ A similarly large quantity of consideration, debate, and thought has gone into formulating and executing foreign policy analyses around the world. Unfortunately, although these funds may have increased the relative security of individual nations at times, and the prevalence of military conflict has gradually declined over many years, the number of people who die as a direct or indirect result of military conflict each year has grown, at least until the early $1990 \mathrm{~s}$.

Scholars and policy makers then began to recognize that even successful examples of territorial security do not necessarily ensure the security of citizens within a state, a fact to which the examples of North Korea and Rwanda attest. With Robert McNamara, ${ }^{17}$ analysts also began to recognize environmental degradation ${ }^{18}$ and natural disasters such as epidemics, floods, earthquakes, and droughts as important threats to security as much as human-made military disasters. ${ }^{19}$ The collapse of the Soviet Union, the reduced threat of a major-power war, and the supposed peace dividend unleashed a wider debate about whether to broaden the concepts of security further..$^{20}$

These debates led to calls to consider security from a global perspective rather than only from the perspective of individual nations and the idea of common security. ${ }^{21}$ More recently, writers have settled on the phrase human security to emphasize the people-centered aspect of these efforts. ${ }^{22}$ The argument of human security in the security literature captured the view that the focus of

${ }^{15}$ Stephen J. Del Rosso, "The Insecure State: Reflections on 'the State' and 'Security' in a Changing World," Daedalus 124(2): 175-207; David A. Baldwin, "Security Studies and the End of the Cold War," World Politics 48(1): 117-41.

${ }^{16}$ UNDP, 1994: Figure 3.1, 48.

${ }^{17}$ Robert S. McNamara, The Essence of Security: Refiections in Office (New York: Harper \& Row, 1968).

${ }^{18}$ Lester Brown, Redefining National Security, WorldWatch Institute \#14 (Washington, DC: WorldWatch, 1977).

${ }^{19}$ Richard Ullman, "Redefining Security," International Security 8 (1993): 123-29.

${ }^{20}$ Jessica Tuchman Mathews, "Redefining Security," Foreign Affairs 68 (Spring 1989): 162-77; Zbigniew Brezinski, "The Cold War and its Aftermath," Foreign Affairs 71 (Fall 1992): 31 49; Theodore C. Sorenson, "Rethinking National Security," Foreign Affairs (Summer 1990); Michael T. Klare, ed., World Security: Challenges for a New Century (New York: St. Martins Press, 1992).

${ }^{21}$ Palme Commision on Peace and Disarmament: Project on World Security-Series of Papers (http://www.rbf.org/pws/public.html).

${ }^{22}$ T. F. Dixon, "Environmental Change and Human Security," Behind the Headlines 48 (Spring 1991): 1-17; Lincoin C. Chen, "Human Security: Concepts and Approaches" in Common Security in Asia-New Concepts of Human Security, Tatsuro Matsumae and Lincoln C. Chen, eds, (Tokai University Press, 1995), 137-147. 
security studies should shift from the state to the individual and should encompass military as well as nonmilitary threats.

\section{The Intersection of the Development and Security Literatures}

The idea of human security has prompted the development and security communities to intersect. The development community saw an opportunity to capture some of the more substantial political interest and superior financial resources associated with military security and foreign policy by linking human security to human development. ${ }^{23}$ Those in the security community were interested in reaching out to conquer new areas as well. ${ }^{24}$ The success of the campaign to ban landmines has also reinvigorated interest in international efforts to enhance human, rather than territorial, security by reducing the human toll of war. ${ }^{25}$

A unifying event occurred in 1994, when the UNDP issued its Human Development Report focused explicitly on the topic of human security. They argued that "human security is not a concern with weapons-it is a concern with human life and dignity." ${ }^{26}$ Human security had four essential characteristics: it is universal, its components are interdependent, it is best ensured through prevention, and it is people-centered. The report also proposed that threats to human security could be grouped in seven categories: economic, food, health, environment, personal, community, and political. Obviously, these categories are neither exhaustive nor mutually exclusive, and they do not completely represent the fundamental or basic aspects of the idea. However, UNDP's main goal was to use human security as the organizing concept for the 1995 Copenhagen UN Conference on Social Development, While it was not used as the basis for the social summit, human security as proposed by UNDP has continued as an organizing concept in the development economics, public health, and the security communities.

\section{Foreign Policies Based on Human Security}

Canada, Norway, and Japan have led the way by incorporating concepts of human security in their official foreign policies. Politicians and other policy makers in many other nations are considering similar moves. These efforts, however, have led to inconsistent definitions and poorly defined, if somewhat

\footnotetext{
${ }^{23}$ Ul-Haq, Reflections on Human Development.

${ }^{24}$ Chen, "Human Security."

25 "The International Campaign to Ban Landmines calis for: An International ban on the use, production, stockpiling, and sale, transfer, or export of antipersomnel landmines. The signing, ratification, implementation, and monitoring of the mine ban treaty. Increased resources for humanitarian demining and mine awareness programs. Increased resources for landmine victim rehabilitation and assistance" (http:/www.tcbl.org/frames/main.html), 10 March 2001.
}

${ }^{26}$ UNDP, 1994. 
related, perspectives. For example, Canada defines human security as "safety for people from both violent and non-violent threats," and narrower focus than the UNDP version. According to Canada's Department of Foreign Affairs and International Trade, human security does not replace national security. Rather, state security and human security are mutually supportive. According to this limited definition, human security is freedom from fear, and human development is freedom from want. They are mutually reinforcing but distinct concepts.

On a practical political level, Canadian foreign policy advocates the strengthening of legal norms and building the capacity to enforce them through efforts such as the Ottawa Convention on Antipersonnel Landmines and the Rome Treaty creating an International Criminal Court. Austria, Canada, Chile; Ireland, Jordan, the Netherlands, Slovenia, Switzerland, Thailand, and Norway have also promoted a more limited human security agenda. These countries focus on antipersonnel landmines, small arms, children in armed conflict, and international humanitarian and human rights law..$^{28}$

Japanese officials have also articulated a foreign policy with human security playing a central role, ${ }^{29}$ but their definition of human security is more inclusive than Canada's. It also differs in some ways from the UNDP definition. According to Japanese foreign policy, "human security comprehensively covers all the menaces that threaten human survival, daily life and dignity-for example, environmental degradation, violations of human rights, transnational organized crime, illicit drugs, refugees, poverty, anti-personnel landmines and other infectious diseases such as AIDS-and strengthens efforts to confront these threats." ${ }^{30}$ Human security has made it onto the G7/G8 summit agendas. The Cologne meeting of foreign ministers in June 1999 issued a communiqué highlighting human security as central to their agendas. The political support and visibility of human security-based foreign policy has also been reflected in the UN Security Council taking on AIDS in Africa, its first discussion of a public health issue. ${ }^{31}$

${ }^{27}$ Axworthy, "Address on Human Security."

${ }^{28}$ Lysøen Declaration: Canada-Norway. At a scnior officials meeting in Ottawa (7-8 December 1998), Canada and Norway agreed to undertake a number of human security issues on a collaborative agenda including the issue of children in armed conflict. They are also committed to follow up on the recommendations made by the Graça Machel Study so as to facilitate the improvement of the situation of war-affected children, to intensify efforts for child protection including an end to the recruitment of child soldiers, and to assist with the rehabilitation and reintegration of war-affected children. Canada, Department of Foreign Affairs and Trade (http:/www.dfait-maeci.gc.ca/menu-e.asp), 10 March 2001.

${ }^{29}$ Keizo Obuchi, Prime Ministerial Address, "In Quest of Human Security," Japan Institute for International Affairs 40 Anniversary Symposium, United Nations University, Tokyo, 11 December 1999.

${ }^{30}$ Ministry of Foreign Affairs of Japan, Diplomatic Bluebook 1999: Japan's Diplomacy with Leadership Toward a New Century (Tokyo: Urban Connections Inc., 1999).

${ }^{31} \mathrm{http}: / \mathrm{www} . u n . o r g /$ News/Press/docs/2000/20000110.sc6781.doc.html, 10 March 2001. 


\section{Problems with Existing Definitions}

The movement to replace traditional ideas of state security and human development with a new human security paradigm continues. Yet even some of the strongest proponents of human security recognize that it is at best poorly defined and unmeasured, and at worse a vague and logically inconsistent slogan. Human security as formulated by UNDP has been criticized as too broad to be useful as a construct for security or foreign policy. Political scientists and others complain that if all the components of well-being are included, the concept of human security will lose its meaning. The common approach of defining human security by providing lists of past humanitarian crises and threats is a very useful descriptive first step, but does not provide a prospective definition of the concept or a disciplined method of deriving or evaluating the elements of the lists.

For example, UNDP's seven dimensions of human security imply a number of potential interrelated and overlapping dimensions centered on human dignity, but do not provide a coherent framework for integrating them into a single concept. ${ }^{32}$ Similarly, Jorge Nef has compiled a number of dimensions of human security and proposed an alternative five-fold classification system based on his analysis of the elements of world system: ecology/environment, economy, society, polity, and culture..$^{33}$ According to Nef, these subsystems are linked by a set of bridges: environment and economy are linked by resources; economy and society, by society forces; society and polity, by brokers and alliances; and politics and culture, by ideology.

A final example of the descriptive list approach to defining human security is the wide-ranging classification scheme of George MacLean.$^{34}$ In this formulation, human security involves the security of the individual in his or her personal surroundings, community, and environment. This includes personal security for the individual from violence or harm; access to the basic essentials of life; protection from crime and terrorism, pandemic diseases, political corruption, forced migration, and absence of human rights; freedom from violations based on gender; rights of political and cultural communities; political, economic, and democratic development; preventing the misuse and overuse of natural resources; environmental sustainability; and efforts to curtail pollution.

We conducted informal off-the-record interviews with politicians and officials responsible for the foreign policy in several countries that describe their policy as in some way based on human security. Virtually every person we spoke with was concerned that there existed no widely accepted or coherent definition of human security and that there were considerable conceptual prob-

32 UNDP, 1994.

${ }^{33}$ Jorge Nef, Human Security and Mutual Vulnerability: The Global Political Economy of Development and Underdevelopment, 2nd ed. (Ottawa: International Development Center, 1999).

${ }^{34}$ George MacLean, "The Changing Perception of Human Security: Coordinating National and Multilateral Responses: The United Nations and the New Security Agenda," United Nations Association in Canada, 1998, (http:/www.unac.org/canada/security/maclean.html), 10 March 2001. 
lems in relating human security, human development, and the development focus on poverty together in the articulation of foreign policy.

With no consensus or theoretical definition, the goal of measuring and enhancing human security is beyond reach. As a result, we cannot yet hope to use this concept to focus the policies of UN agencies and nations' bilateral aid agencies to improve the plight of human beings worldwide. The present inconsistent state of discussion about human security also means that energy in the academic literature cannot yet be productively or efficiently captured to foster these important developments in policy making.

\section{Defining Human Security}

In common usage, the word "security" denotes freedom from various risks. The Oxford English Dictionary defines the word as, "The condition of being protected from or not exposed to danger; safety.... Freedom from care, anxiety or apprehension; a feeling of safety or freedom from or absence of danger." In a similar vein, Social Security in the United States is an institution meant to guarantee that individuals do not fall below a minimum income threshold during retirement.

The idea of security thus contains two key elements: an orientation to future risks and a focus on risks of falling below some critical threshold of deprivation. Security is not synonymous with the average level of future well-being, but instead focuses on the risks of being severely deprived. My security today is not only a function of my well-being today, but also the prospects of avoiding states of great deprivation in the future.

Our criteria for an optimal definition is one that formalizes what appears to be the emerging international consensus on human security, is rigorous, precise, and logically consistent, and is useful in making public policy. To lay the groundwork for this definition, we briefly review the concept of well-being. Then we propose a generalized concept of poverty based on falling below critical thresholds in any domain of well-being. We define an individual's human security as his or her expectation of years of life without experiencing the state of generalized poverty. Population human security is then an aggregation of individuals' human security.

\section{Domains of Well-Being}

The meaning of human well-being has been debated for more 2,500 years and is reflected in an extensive academic literature..$^{35}$ Different formulations of the

\footnotetext{
${ }^{35}$ For example, Thomas Scanlon, What We Owe Each Other, (Cambridge, MA: Belknap Press of Harvard University Press, 1998); James Griffin, Well-Being (Oxford, UK: Oxford University Press, 1986); Amartya K. Sen and Bermard Williams, eds., Utilitarianism and Beyond (Cambridge, UK: Cambridge University Press, 1982); Sen, Inequality Reexamined; Tibor Scitovsky, The Joyless Economy (New York: Oxford University Press, 1982), 103-28; Thomas Scanlon, "Preference and Urgency," Joumal of Philosophy 72 (November 1975); 655-69; Jon Elster and John E. Roemer, eds., Interpersonal Comparisons of Well-Being (Cambridge, UK: Cambridge University Press, 1991).
} 
concept include those that can be categorized as subjective mental states (such as pleasure or comfort), or the degree of objective satisfaction of subjective desires and objective states. ${ }^{36}$ An important aspect of these theories is the principle invoked to decide which components of subjective or objective states should be included in an overall conception of well-being. ${ }^{37}$ For example, some domains would seem to be intrinsically valued, such as health, freedom, or knowledge; whereas others are important means of achieving well-being, such as wealth; or derivative, such as the absence of crime or natural disasters.

Earlier proposed definitions of human security were sometimes criticized for being overbroad: by trying to encompass everything, they wound up not meaning anything. For our definition, we include in human security only those domains of well-being that are essential or extremely important. We do not pretend to have a unique way to put this normative concept into operation. However, we think that one helpful approach may be to include only those domains of well-being that have been important enough for human beings to fight over or to put their lives or property at great risk. Other components of well-being may be important, useful, or desirable, and thus should be included in composite measures of well-being such as efforts like the Human Development Index, and UNDP; but they would be excluded from our definition of human security.

Once these essential elements of well-being are identified, our framework gives us considerable latitude in how each is operationalized. We do not even require the domains of well-being to be independent or logically distinct. They can be derivative, intrinsic, or only indirectly measurable. The resulting definition and measure of human security can still be the same. For example, even the extreme case of two fully repetitive domains would pose little conceptual disadvantage as long as both are measurable: given how the categories are combined in constructing a measure of generalized poverty, no numerical change would occur in our index of human security. All that we require is a list of measurable and possibly overlapping components of well-being that, when taken together, constitute what most people mean by well-being.

Although a mutually exclusive and exhaustive definition of well-being based on independent and intrinsic domains that are all essential would be preferable in its own right, and we applaud scholars who continue their long quest toward this goal, our proposed definition of human security is not greatly affected by these issues.

\section{Generalized Poverty}

Because security is based on the risk of severe deprivation, it depends heavily on the concept of poverty. However, poverty is most often defined in terms of

\footnotetext{
${ }^{36}$ Elster and Roemer, Interpersonal Comparisons.

${ }^{37}$ Robert E. Goodin, "Laundering Preferences" in Jon Elster and Aanund Hylland, eds., Foundations of Social Choice Theory (Cambridge, UK: Cambridge University Press, 1986), 75-101.
} 
only one instrumental factor-income.$^{38}$ For our purposes, we take advantage of the literature that defines poverty more broadly to include the deprivation of any basic capabilities. ${ }^{39}$ This broader conception has many advantages, in addition to fitting our definition well. For example, if a person were about to enter prison, food and shelter would be guaranteed, but the loss of freedom would clearly makes that person impoverished. To distinguish this from being below a particular level of income, we refer to this broader concept as generalized poverty.

According to our definition, a person is in a state of generalized poverty whenever he or she dips below the pre-defined threshold in any of the component areas of well-being. Our dichotomization of each component of well-being is based on the belief that there is a qualitative difference in life experience above and below the threshold. For example, the difference between not hav. ing enough food and nutrition to survive and having enough food is fundamentally different from the difference between having enough food to survive and having food that also tastes especially good.

For some domains of well-being, the thresholds may be set below the minimum observed value so that individuals cannot be in a state of generalized poverty because of their level on that domain. For example, owning more cars would normally improve one's well-being, but owning zero cars would not put one into a state of generalized poverty. For these purposes, even some entire domains of well-being, such as creativity, might be excluded in this way.

A key advantage of our definition of generalized poverty is that it does not require a set of weights to be developed to "equalize" the different domains of well-being. Since a person missing even one of these essential elements for any part of a year would be considered impoverished, the only arbitrary element in the definition is the threshold for each domain of well-being. Moreover, the policy world has much experience with choosing threshold values for income and many other areas (such as to decide whether individuals qualify for certain programs). Although these thresholds are arbitrary and can be improved in theory in some ways (at the cost of simplicity), they are frequently used because they are fairly accurate reflections of people's life experiences and are simple to use. In addition, small changes in these thresholds do not always produce as large changes in population-based indexes as weights would in an aggregate well-being index.

For example, we treat both (1) being tortured and (2) being tortured and starving, as impoverished and unacceptable conditions. Condition 2 may be harder to remedy than 1 , but we do not have to decide how much worse 2 is than 1 in order to decide that the person is experiencing a state of generalized poverty. Similarly, few would argue that persons to be tortured four times in the

${ }^{38}$ See, for example, World Bank relative and absolute poverty estimates, 1999.

${ }^{39}$ Sudhir Anand and Amartya K. Sen, "Concepts of Human Development and Poverty: A Multidimensional Perspective," Human Development Papers (New York: UNDP, 1997); Sen, Inequality Reexamined. 
next year are secure no matter how high their income. Rather, being tortured in the next year will put them in a state of deprivation or generalized poverty. The prospect of this outcome makes them insecure today. Of course, for analytical purposes other than defining human security, definitions of generalized poverty that include trade-offs between the level of achievement in one domain of wellbeing versus another may be appropriate, particularly when individuals freely choose to balance some domains of well-being against others.

Since we do not need to create and justify weights in combining domains, we can include as many other domains as the international community agrees on. For example, we can include education as a domain of well-being, even though it was once not considered an essential element for having a minimal
level of well-being.

In our view, the set of thresholds used to define generalized poverty for the purposes of measuring human security should be general and not context- or region-specific. Human security is a global issue and a global challenge. For example, if income is used as an instrumental proxy for a number of intrinsic domains of well-being, then a single income threshold should be used in all populations. The alternative view that poverty is a relative concept, and hence the poverty threshold should be context specific, is a reasonable and practical approach in a world with hugely varying income levels. However, our goal, and we believe the goal of most others, is to treat all people, regardless of location, as belonging to the same global community; and hence one common threshold applies. The resulting concept would then also be comparable across individuals and populations.

\section{Individual Human Security}

Building on the concept of generalized poverty and the forward-looking nature of our conception of security, we define Years of Individual Human Security (YIHS) as the expected number of years of life spent outside the state of generalized poverty. We give details in the appendix. This concept reflects both the individual's prospects of being alive at each point in time and his or her chances of being above the generalized poverty threshold, if alive. For example, if a 40 -year-old women has a life expectancy of 35 additional years but only a 50 percent chance in each future year of being above the generalized poverty threshold, her individual human security would be 17.5 years. The unit of measurement for individual human security is thus a life-year, which is familiar and easy to interpret. ${ }^{40}$ YIHS is always less than or equal to an individual's life expectancy. If an individual faces no risks of falling below the generalized poverty threshold, YIHS equals life expectancy; nonzero risks of generalized poverty reduce YIHS further.

\footnotetext{
${ }^{\text {*0 }}$ Christopher Murray, J. A. Salomon, and C. Matthews, "A Critical Examination of Summary Measures of Population Heaith," Bulletin of World Health Organization 78 (No. 8, 2000): 981-994.
} 
Although YIHS is most useful for developing the population measures of human security described in the next section, we also define a measure that may be more intuitive for some purpose at the individual level of analysis. Thus, Individual Human Security (IHS) is the proportion of the lifespan that a person could reasonably aspire to that he or she can expect to spend outside the state of generalized poverty. This measure, which ranges from zero to one, controls for differences in age. YIHS and IHS are objective measures and so may diverge from an individual's perceived human security. While enhancing perceived human security is an important goal in its own right, the focus of our concern is on objective levels of individual and population human security.

We have formalized these measures of human security as including discount rates so that risks of entering into a state of generalized poverty in the distant future may be weighed as less important than risks in the near future. Discounting future well-being, or in the present case the risks of being impoverished, has long been debated. ${ }^{41}$ While it is our general view that future risks should be considered as important or nearly as important as more proximal risks of poverty, the formulation allows for any plausible discount rate. Current practice in a number of fields, such as cost-effectiveness analysis of health interventions, has slowly gravitated to using low positive discount rates of 3 percent or less per year..$^{42}$ Obviously, once the hard work is done to collect the necessary measures, alternative discounting schemes could also be computed for comparison.

\section{Population Human Security}

For the purposes of informing debates on development and security policy, we also provide a definition of population years of human security based on two ways of aggregating YIHS. The simplest measure is the average of YIHS for everyone in the relevant population. If YIHS is 25 for half the people and 35 for the other half, then population human security would be 30 . For many uses, this direct average is the most appropriate measure. However, it is sensitive to differences in the population age distribution. If one population is older on average than another, ceteris paribus, it will have a lower population human security. In a strict sense, this is correct. The older population has an expectation of living fewer years above the generalized poverty threshold. But for some comparative purposes, we might like a measure that is unaffected by the age

${ }^{41}$ F. P. Ramsey, "A Mathematical Theory of Saving," Economic Journal 38 (December 1928): 543-59; R. C. Lind, ed., Discounting for the Time and Risk in Energy Policy (Baltimore: Johns Hopkins University Press, 1982); Stephen A. Marglin, "The Social Rate of Discount and the Optimal Rate of Investment," Quarterly Journal of Economics 77 (February 1963): 95-111; Derek Parfit, Reasons and Persons (Oxford, UK: Oxford University Press, 1984); Amartya K. Sen, "Isolation, Assurance and the Social Rate of Discount," Quarterly Journal of Economics 81 (February 1963): 1123-4.

${ }^{42}$ For example, Marthe R. Gold, Joanna E. Siegel, Louise B. Russell, and Milton C. Weinstein, eds., Cost-Effectiveness in Health and Medicine (New York: Oxford University Press, 1996). 
distribution of the population. For such comparative use, we propose to compare groups on the basis of population years of human security at birth. ${ }^{43}$ The average value of YIHS for newborns today, just like period life expectancy (which is life expectancy at birth), is not affected by the age structure of the population and to a considerable extent reflects a broad range of future risks of survival and generalized poverty in the future.

Both population years of human security and population years of human security at birth are measured on the same intuitive scale as the familiar measures of life expectancy and life expectancy at birth, respectively. They measure the average number of years members of a given population can expect to live (starting from either observed ages or at birth) outside of the state of generalized poverty.

Both concepts exclude future generations in their calculation and thus avoid the standard paradoxes that would otherwise result. For example, without discounting, including future births means that population human security will be the same for almost all populations far enough into the future. Although challenging examples can be found (such as forecast epidemics of infant diseases), we believe that defining population human security as a function of currently living individuals is a reasonable and practical approach. Given the state of the methods of risk assessments, plausible measures of population human security at birth would need to reflect known risks over the succeeding century. This is already a wide window of evaluation, and extending it further into the future is likely to be empirically impractical.

We also exclude from our population measure anything that affects the security of institutions, governments, or other organizations, unless it also affects individuals. This conception of population human security is thus a natural evolution of the literature since Richard Ullman wrote of focusing security on individuals rather than states. ${ }^{44}$

\section{Measuring Human Security}

To measure human security in practice, a set of domains of well-being must be selected. For each domain, a practical indicator must be constructed, as well as the threshold value below which an individual will be defined to be in a state of generalized poverty. Two standard approaches to measuring well-beingmoney-metric utility and the human development index-are instructive examples for this purpose.

\footnotetext{
${ }^{43}$ Another option for an age distribution-independent definition of population human security is to use a standard age distribution to calculate age-standardized population human security (See O. B. Ahmed et al., "Age Standardization of Rates: A New WHO Standard," GPE discusion paper, no. 31 (Geneva: World Health Organization, 2000). This measure would reflect the complete range of risks of survival and generalized poverty over age and time but has the disadvantage of requiring the selection of a necessarily arbitrary population distribution for age standardization.

${ }^{44}$ Ullman, "Redefining Security."
} 
Some analysts favor using income per capita as a general, all-purpose measurement of well-being, as is amply illustrated by the international focus in policy debates on income per capita. This approach is founded on the notion that each individual can best use the resources they command to maximize their own well-being and that interpersonal comparisons can legitimately be made on the basis of total income. The problems with this approach are well known, ${ }^{45}$ and when measurement is feasible, most analysts try to include other domains as well. For example, three domains were included in the Human Development Index: ${ }^{46}$ income per capita, health, and education. Income per capita was not used as an intrinsic domain of well-being but as instrumental for the attainment of many other domains. Health and education were selected because they were considered intrinsic domains of well-being and could be practically measured.

We begin with the Human Development Index domains and so also use income per capita as instrumentally related to several domains of well-being, and also include health and education. Threshold levels of economic well-being and health are clearly important enough to provoke violence. Education per se has not been that important, and so a plausible case might be constructed that it could be omitted; but people have often fought over the cultural values reflected in education. In addition, we wish to capture contributors to generalized poverty related to other basic freedoms. The UNDP recognized the importance of political freedom and democracy, but could not find generally acceptable measures or weights and so could not include it with their other measured domains. Since we only need a threshold, and no weights, it will be somewhat easier for us to include variables like these. Thus, our suggestion for a parsimonious set of domains for measuring human security would be income, health, education, political freedom, and democracy. Many other domains of wellbeing come in indirectly through these. In addition, any aspect of well-being that directly affects life expectancy, such as the environment or biodiversity, will to an extent be automatically included in our measure of human security without having to establish a separate domain or threshold.

For each domain explicitly included, we must select an indicator or indicators that reflect our current state of information, as well as the threshold value below which an individual would be in a state of generalized poverty. We now suggest measures of each of these domains, but we emphasize that our framework can easily accommodate any number of additional domains.

\section{Domain-Specific Measures}

Although the System of National Accounts (SNA) was developed in the 1950s and has been nearly universally adopted, many variants of income per capita

${ }_{45}^{45}$ World Bank, World Development Report, 2000-01 (New York: Oxford University Press, 2000).

${ }^{46}$ UNDP, 1990. 
could be used ${ }^{47}$ Because we emphasize comparing the purchasing power of different individuals across the world, we believe a good measure is GNP per capita converted into international dollars using purchasing power parities. ${ }^{48}$ The World Bank has proposed that the global definition of absolute (economic) poverty is less than $\$ 365$ per capita per year in 1985 international dollars ${ }^{49}$ and this definition has now been widely adopted in the international community (for example, World Bank, DFID). According to this definition, 1.3 billion individuals now live in poverty. ${ }^{50}$ Like any threshold, this one is arbitrary but has been set at such a low value that no one can credibly argue that individuals with less than $\$ 365$ per capita are not in generalized poverty. While a good case can be made for raising the poverty threshold, our goal is to codify existing international consensus, and this is the closest we have at present.

Health factors are included in the definition of human security in two distinct ways. First, survival is a critical component of human security. Increasing mortality rates reduce life expectancy and YIHS, ceteris paribus. Fortunately, mortality forecasting is an active area of scholarly research and policy advice. ${ }^{51}$ Second, individuals who are alive can fall below a threshold of health status that places them in a state of generalized poverty (for example, being paralyzed from the neck down). Considerable progress has been made in the development of comparable measures of the nonfatal dimensions of population health. ${ }^{52} \mathrm{~A}$ variety of survey instruments have been developed such as SF-36, ${ }^{53}$ Euroqol, ${ }^{54}$ and WHODAS,,${ }^{55}$ which can be used to measure various aspects of

${ }^{47}$ There are two major choices. First, income per capita can be calculated on the basis of goods and services produced within a country (Gross Domestic Product) or it can be corrected for net property income from abroad (Gross National Product). The distinction is important for countries where remittances or income from investments abroad is substantial. The other key choice is the method of converting incomes per capita in national currency units into a common metric for the purposes of cross-national comparisons. Because official exchange rates do not reflect purchasing power parity for nontraded goods and services such as primary education, an alternative method based on measuring prices and computing purchasing power parities has been developed. See Robert Summers and Alan Heston, "The Penn World Table (Mark 5): An Expanded Set of International Comparisons, 1950-1988," The Quarterly Journal of Economics 106 (2): 327-68. Such PPP based comparisons are expressed in "international dollars," which is U.S. dollars in purchasing power terms.

${ }^{48}$ The two main estimates of purchasing power parity, based on GDP and GNP per capita, are the Penn World Tables (Summers and Heston 1991) and the World Bank (World Development Indicators 1999), respectively. Unfortunately, the correlation of these two measures is not high enough to make the choice ignorable.

${ }^{49}$ World Bank, 1990.

${ }^{50}$ World Bank, 1999.

${ }^{51}$ World Health Report, 1999 and 2000.

${ }^{52}$ Murray, Salomon, and Mathers, "A Critical Examination."

${ }^{53} \mathrm{~J}$. Ware, SF-36 Health Survey, Manual and Interpretation Guide-The Health Institute, New England Medical Center, Boston, Massachusetts.

${ }^{54}$ EuroQuol Group, "A New Facility for the Measurement of Health-Related Quality of Life," Health Policy 16 (1990): 199-208.

${ }^{55}$ WHO-DAS, "Disability Assessment Schedule Version 3.1a" (WHODAS-II), Geneva, World Health Organization, 1999. 
individuals' health. In parallel, work on how individuals value time spent in different health states provides a basis for an overall assessment of the severity of health states ${ }^{56}$ Health states are valued on a scale from 0 (death) to 1 (full health). Severe states such as quadriplegia score around 0.2 and severe depression is $0.6 .^{57}$ We would suggest that any individual in a health state less than 0.25 is in a state of generalized poverty.

Most of the rich academic literature measuring democracy and political freedom considers each separately. ${ }^{58}$ One of the most commonly used measures is provided by Freedom House, a nonprofit, nonpartisan organization. Freedom House judges democracy by quantifying political rights and political freedom by quantitative measures of civil liberties, which "include the freedoms to develop views, institutions, and personal autonomy apart from the state." 59 Over 800 other measures of political freedom and democracy have been constructed, ${ }^{60}$ but almost all focus on evaluations of governments rather than the political security of their citizens. This means that to measure the political component of generalized poverty properly, we need additional work. One reasonable threshold for the generalized poverty level for democracy could be the right of an individual to vote in at least one free and fair election (not necessarily national) that affects some important aspect of that person's life. This is quite a minimal level of democracy that the international community would surely want to improve, but without this right a person should clearly be seen as severely deprived. The analogous country-level measure might be the fraction of adults who can participate in such elections. Interestingly, such a measure would likely be greater than 0 percent and less than 100 percent in all but a few countries.

The two main options for measuring educational attainment include literacy and average years of schooling. The advantage of literacy is that it incorporates a qualitatively meaningful threshold of educational attainment in its definition. Most would agree that being illiterate places an individual in a state of generalized poverty. On the practical front, the problem with literacy is that it is notoriously difficult to compare across countries because self-reported lit-

\footnotetext{
${ }^{56}$ P. F. M. Krabbe, M. Essink-Bot, G. J. Bonsel, "The Comparability and Reliability of Five HealthState Valuation Methods," Social Science and Medicine 45 (December 1997): 1641-52; J. Brazier, T. Usherwood, R. Harper, and K. Thomas, "Deriving a Preference-Based Single Index from the UK SF-36 Health Survey," Journal of Clinical Epidemiology 51 (November 1998): 1115-28; E. Nord, "Methods for Quality Adjustment of Life Years," Social Science and Medicine 34 (No. 6, 1992): 559-69.

${ }^{77}$ Christopher Murray and Alan Lopez, eds., The Global Burden of Disease, Global Burden of Disease and Injury Series: vol. 1. (Cambridge, MA: Harvard University Press, 1993).

${ }^{58}$ See Kenneth A. Bollen and Pamela Paxton, "Subjective Measures of Liberal Democracy," Comparative Political Studies 33 (February 2000): 58-86.

${ }^{59}$ The methods of Freedom House can be found at http://www.freedomhouse.org/survey99/ method/.

${ }^{60}$ Kenneth A. Bollen and Pamela Paxton, "I02532: Cross-National Indicators of Liberal Democracy, 1950-1990." Data set at the Inter-University Consortium for Political and Social Research, Ann Arbor, Michigan (http://www.icpsr.umich.edu., 1999).
} 
eracy differs substantially across countries. Average years of schooling, on the other hand, is a more robust measure of educational attainment. ${ }^{61}$ An appropriate threshold for average years of schooling might be five or six years, which reflects basic primary education. If a comparable measure of literacy becomes available, we would propose to use it also.

\section{Data Needs}

Measuring population human security requires as its starting point good information on the current and past levels of income, health, education, democracy, and political freedom for individuals in different populations of the world. To estimate generalized poverty, however, we need information on individuals within populations simultaneously for these key variables. As the definition of generalized poverty is based on falling below the critical threshold in any of these domains, we require information on the levels of each variable for each individual. In other words, information on health that cannot be related at the individual level to the information on income or political freedom cannot be used alone to estimate generalized poverty for a population.

In practice, we could use available detailed data collections such as national accounts or vital registration to measure the variables separately, and a much smaller study to estimate their joint distribution. As a last resort, methods of ecological inference could be used to infer the joint distribution.$^{62}$ Scholars have made substantial progress moving from national aggregate data on income to information on the distribution of income. ${ }^{63} \mathrm{We}$ believe that the natural next step, consistent with trends in data collection and with the movement toward human security, is to broaden the collection scheme to cross-domain measures at the individual level. In some cases, adding information on education and proxies of wealth or income to routinely collected health information may be relatively inexpensive. This would be especially valuable since this health information is already collected in relatively standard forms in almost all countries.

Not withstanding this agenda for the future development of generalized poverty information systems, new methods need to be developed and applied to estimate the joint distribution of health, education, income, and political freedom. Fortunately, much can be done. For example, the World Health Organization has a project to use national income and expenditure surveys, along with satellite mapping of the world's population and several geographic factors, to map the location of the world's economically impoverished. Preliminary re-

\footnotetext{
${ }^{61}$ Average years of schooling for the population over 15 or over 25 has been called "human capital." See Jong Wha Lee and Robert Barro, "International Comparisons of Educational Attainment," Journal of Monetary Economics 32 (December 1993).

${ }^{62}$ For example, Gary King, $A$ Solution to the Ecological Inference Problem: Reconstructing Individual Behavior from Aggregate Data. (Princeton: Princeton University Press, 1997).

${ }^{63}$ See the Wider database on income inequality-http://www.wider.unu.edu/wiid/wiid.htm.
} 


\section{FIGURE 1}

Estimated Distribution of the Poor in Africa and other Regions of the World, 1998.

(Preliminary Results Based on The World Health Organization Mapping

The Poor Project).

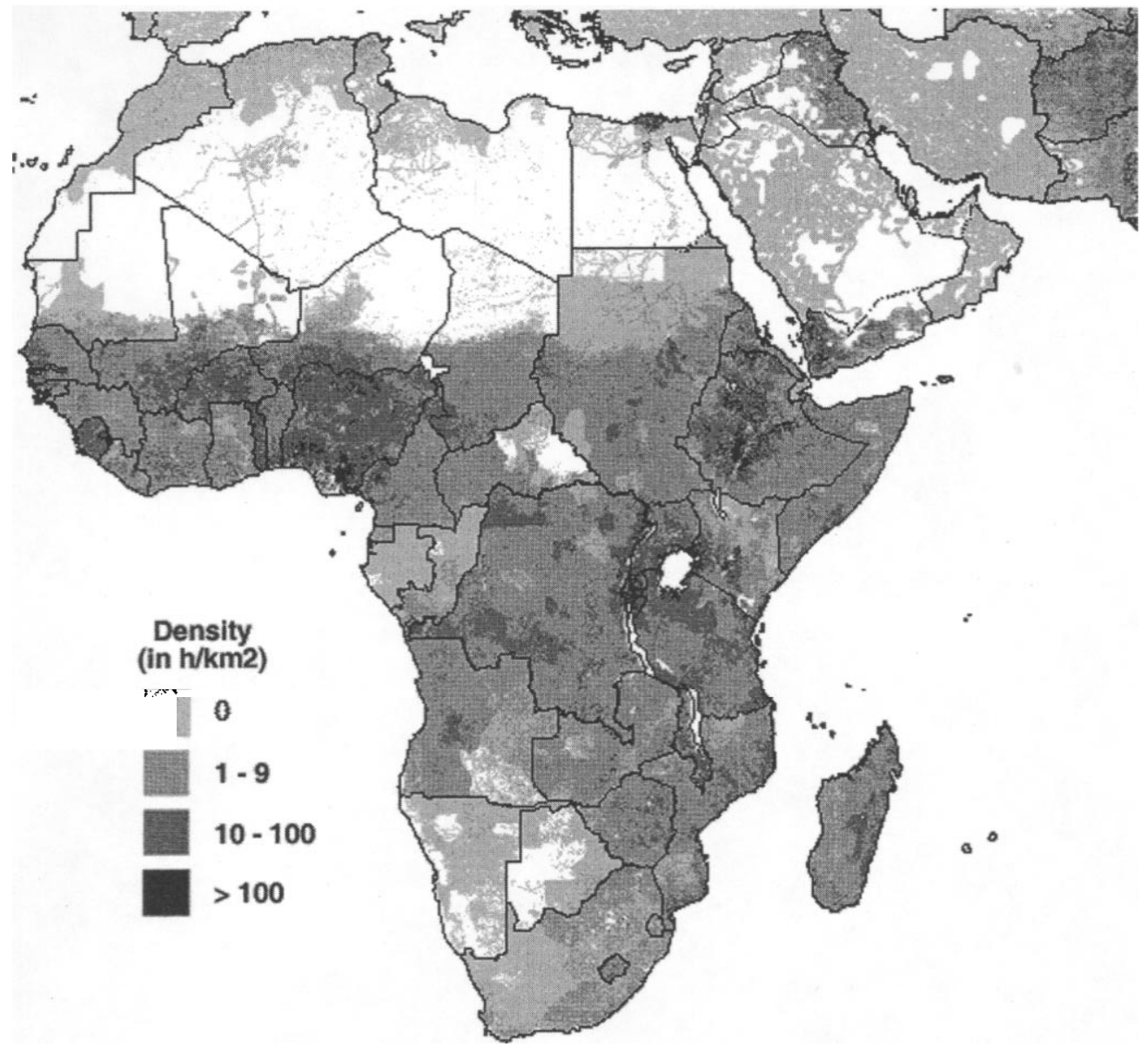

Note: This map demonstrates the feasibility of locating the economic poor in one of the most data-poor regions of the world. Darker areas indicate a higher density of poor people. Lighter areas indicate the relative absence of poor people (the Sahara Desert in Northem Africa, where few people live, is a prominent pattern in the graph).

sults of this project are illustrated in Figure 1, which shows the density of poor individuals per square kilometer for each continent. This mapping of the world's poor amply illustrates the major difference between those in absolute poverty and individuals whether rich or poor who live in the poorest countries. For example, in China, with an income per capita in 1997 International Dollars of 3070 per capita, over 200 million are estimated to be in poverty. ${ }^{64}$ Other parts 
of the world with high densities of poor include Bangladesh, the Ethiopian Highlands, the Ganges Valley, and the Great Lakes region of Africa and Nigeria. Work is underway to use other sources such as demographic and health surveys to estimate the distribution of individuals in different states of health. ${ }^{65}$

Human security is a forward-looking concept: to measure it today we must project generalized poverty and survival tomorrow. Projections require the development of methods of risk assessment with predictive validity. Such models can best be developed if relatively long historical data bases are available so that the relationship between generalized poverty in each domain, and key social, economic, cultural and political factors, can be explored. Risk assessment is thus a two-stage process. Key factors in accounting for large changes in human security, such as wars, global warming, earthquakes, other natural disasters, and economic crises must be identified prior to projecting generalized poverty itself. In some cases, the areas of health, income, education, and political freedom require as a first step models to assess the risks of these events. Below, we use the challenge of risk assessment of military conflict to illustrate directions for progress in measuring human security.

One important purpose of measuring human security is to provide individuals with better information on their own human security. By so doing, we will tend to increase each individual's perceived human security because humans tend to overestimate threats to their own security. However, measuring human security will also be a critical input to public policy debates on how to enhance population human security. Individual risk assessment models naturally lead to actions to prevent or decrease the prospects of generalized poverty. Measuring human security will also focus the international foreign policy debate on the key contributors to human insecurity and thus improve public policy. To facilitate these goals, we propose that necessary data bases and models be developed that allow for the annual calculation of this human security index. As with all efforts at comparative assessment, annual or periodic reporting of population human security will help all countries understand their situation and inform them about where to make improvements.

\section{ENHANCING Human SECURITY}

Human insecurity can come from any source that increases the risk that people will remain in or enter into a state of generalized poverty. Since generalized poverty is a state that is often difficult to exit, existing in this state is one of the major threats to human security - that is to being in generalized poverty in the future. Others include crime, military conflict (group violence), nonpeaceful transfers of governmental power, diseases and other public health problems,

\footnotetext{
${ }^{63}$ Emmanuela Gakidor, Christopher Murray, and Julio Frenk, "A Framework for Measuring Health Inequality," World Health Organization: Discussion Paper, 29 July 2000 (http:/www.nt.who.int/ whosis/statistics/discussion_papers/papersos.pdf).
} 
acute environmental disasters (floods, droughts, earthquakes, weather storms, hazards from space, contamination), long-term environmental changes (global warming, ozone hole, water shortage, pollution), and economic crises.

Some components of generalized poverty, such as income, health, and education, have witnessed considerable global progress in the last half-century. For example, the dramatic success of the international community in contributing to the expansion of global life expectancy from 46.5 years in 1950-1955 to 65.4 years in $1995-2000^{66}$ is an example of the progress that can be made.

\section{Categories of Efforts to Enhance Human Security}

We categorize efforts to enhance human security, ranging from ex ante to ex post, as risk assessment, prevention, protection, and compensation. Risk assessment involves improving and communicating knowledge of the risks that particular populations will enter into or remain in a state of generalized poverty. Prevention includes efforts to reduce these risks. Protection includes those actions that decrease the harm from the events if they occur. Compensation includes efforts to provide financial or in-kind payments to those in generalized poverty. To arrive at these categories, we began with the scheme originally developed by Lincoln Chen ${ }^{67}$ and then slightly expand it to highlight the importance of risk assessment as distinct from prevention.

This categorization can be used to construct more detailed operational strategies for increasing human security, based on new public policies and academic research. For example, military conflict risk assessment should include research on forecasting military conflict, communicating the risks to those for whom it can make a difference, and developing surveillance systems. Prevention involves estimating causal models of war, identifying modifiable causes, using risk assessments to target conflict reduction interventions, UN Security Council efforts, and national and international deterrence efforts. Protection from military conflict includes trying to change the weaponry of war, such as the campaign to ban landmines and cluster bombs, reinvigorating and extending the international laws that protect noncombatants, and protecting social service delivery and public health systems from combat. Compensation includes war insurance schemes (with risk rated on the basis of existing forecasting models) and various types of humanitarian assistance.

\section{Advantages of Improving Risk Assessment}

Even a cursory examination of the major threats to and strategies for enhancing human security highlights risk assessment as the major important and underin-

\footnotetext{
${ }^{66}$ United Nations, World Population Prospects, Vol. 1, Comprehensive Tables (New York: United Nations, 1998).

${ }^{67}$ Chen, "Human Security."
} 
vested area. Risk assessment is critical even for merely measuring population human security, but the advantages of improving risk assessment go far beyond simple measurement.

First, improving methods so that meaningful risk assessment can be undertaken is an important research endeavor in its own right. This type of knowledge in and of itself should be considered a public good. In addition, better knowledge of specific risks might be used by the international community to make more effective public policy. Many efforts at prevention require knowledge of risks; for example, effective response to human security risks is enhanced by early warning systems and hence good risk assessment.

We also know that much psychological and social-psychological research demonstrates that people tend to overestimate risks of the components of generalized poverty ${ }^{68}$ By providing high quality risk assessments and disseminating this information to the public, individual perceived human security in many settings can be enhanced. In those settings where individuals underestimate their human insecurity, better risk assessment will allow them to take action at the individual, household, or government level to mitigate against the impact of these risks if they occur.

Third, even if individuals' assessments of their average future well-being are unbiased (that is, correct on average), psychological research indicates that people tend to evaluate the uncertainty in forecasts incorrectly. As such, better risk assessment that is widely and informatively disseminated can increase individual perceived human security directly by reducing forecast variances. Perhaps most obviously, better risk assessments make new interventions possible. For example, accurate hurricane forecasts eliminate most of the immediate public health risk of these severe weather events.

Our approach to using risk assessment in the definition of human security also has the advantage of encompassing other important problems not affecting current human well-being. For example, biodiversity, which is seen by the scientific community as one of the most important global problems, has little or no effect on current well-being. Approaches that provide an agenda for the international community that are not forward-looking would either ignore biodiversity or append it to the agenda in a logically incoherent fashion. Under our approach, even though biodiversity has no effect on current well-being, it is essential in maintaining future well-being and hence plays a central role in improving human security.

Risk assessment is important for forging policies based on the forward looking concept of human security, which can be far more effective than basing policy on current well-being or generalized poverty. Since fighting the last war is obviously not the goal of the international community, we need to prepare responses to what is likely to occur and not merely because prevention is less

${ }^{68}$ Amos Tversky and Daniel Kahneman, Judgment under Uncertainty: Heuristics and Biases (New York: Cambridge University Press, 1982). 
costly than post-hoc responses. We hope that by illuminating the central role of risk assessment in human security that we are able to point to areas where the academic community can help. Risk assessment is under-researched in some areas and undervalued in others. Most of the social sciences, for example, have an understandable focus on estimating causal effects. What scholars need to understand, however, is that this focus need not come at the expense of models that forecast well. Forecasts are often observable implications of the same models used to estimate causal effects and can also be used to validate those same models. Put in reverse, many causal models now used can be marshaled to improve our forecasts and hence our measurement of human security.

\section{ConCluding Remarks}

We designed our version of human security to be logically rigorous and to satisfy what appears to be the outline of an emerging normative consensus in the international community. As we go to press, we can report on a commitment from the World Health Organization to develop and apply new survey tools to measure health and related domains of human security that follow the suggestions in this article. In addition, we note that in a recent speech, Mexican President Vincente Fox has adopted the notion of human security offered here.

\section{Normative Decisions}

Our concept is based on the security of human beings, rather than the protection of state boundaries, with each individual contributing equally to population human security. The definition is forward looking: an individual's current security is a function of her or his future prospects. Most distinctively, human security is a function of the risk of being below a threshold of well-being, what we call a state of generalized poverty, rather than average levels of well-being.

Using generalized poverty means that a policy based on human security focuses effort primarily on human beings in the most dire situations. This is a logical extension of what was effectively the perspective of the international community in the domain of health when over the last forty years it generated unprecedented increases in the human life span by first addressing severe childhood illnesses. The alternative view would be to focus on increasing average levels of human well-being (otherwise known as human development). While we do not think human security has any necessary, absolute, or lexicographic priority as a goal of social policy in comparison to human development, most in the international community seems to believe that it should have some priority except in somewhat unusual situations.

Recent academic debates have led to related distinctions. For example, the prioritarian view holds that we should be interested in improving the well-being of everyone with a special concern for the well-being of the worst off. ${ }^{69}$ This

${ }^{69}$ Larry S. Temkin, Inequality (New York: Oxford Ethics Series, Oxford University Press, 1993). 
view can be distinguished from the classical egalitarian perspective, which is concerned with the entire distribution of well-being across individuals. Thus, an egalitarian might agree with a public policy that sacrifices a degree of wellbeing among the best off in order to reduce inequality, but in some cases a prioritarian would object.

Any priority for human security over human development should not be considered absolute, and we would not argue against public policy that enhances human development simply because human security had not been maximized first. But we believe that the international development and security communities are primarily focused on enhancing what we call human security. One way of thinking about these normative preferences is to derive them from the deeper goal of maximizing global human utility. From this perspective, the issue is how we make interpersonal utility comparisons. According to our interpretation of the emerging consensus of the international community, a small increase in well-being across the generalized poverty threshold produces a considerably larger change in utility than all but the most extreme changes in human well-being at other levels. If this is true, then the priority of human security over human development is an automatic consequence.

\section{Agenda for Foreign Policy and Scientific Progress}

The definition and measure of human security offered in this article are intended to formalize the emerging consensus in the international community over some of its most central goals. Since the idea of human security is to improve the lives of people rather than improve the security of national borders and key issues cross these borders, coordinated action by the international community seems essential. Continued linkages and cooperation among governments, international organizations, nongovernmental organizations, and other parts of civil society will also be important.

If this is a reasonable statement of the emerging consensus, future directions for development and security policies will be greatly affected. We now consider examples of policy and research strategies that would be affected within the four strategies for improving human security-risk assessment, prevention, protection, and compensation.

One of the areas with the largest potential gains is improving risk assessment for the key causes of generalized poverty. Building the capacity in data bases and methods to undertake better risk assessment should be a central component of a human security-focused foreign policy. The potential for improved risk assessment seems substantial in developing surveillance systems for new diseases, for example. Similarly, recent progress in risk assessment methods in political science means that for the first time some military conflicts can be accurately predicted, which may mean that risk assessment for some other key causes of human security can also be rapidly improved. Such efforts could be greatly enhanced by forging new interdisciplinary ties. For example, political 
scientists have focused almost exclusively on elite political decisions to go to war, rather than war's ultimate public health consequences, and hence on only one aspect of risk assessment and prevention. Public health professionals have not taken advantage of these developments, but have much to contribute in the areas of protection and compensation that political scientists have not engaged ${ }^{70}$

Better prevention strategies could be built on improved risk assessment. For example, in the area of military conflict, better causal models and risk assessments might provide the opportunity for more focused foreign policy interventions to reduce the risk of conflict. Information given to the public in countries or communities with elevated risks of conflict may in and of itself decrease the risk of conflict. Other strategies for prevention that have been proposed and seem likely to be productive include improved international and national monetary institutions to reduce the risk of economic crises, carbon-trading agreements to reduce green-house gases and the risk of global climate change, and improved rapid response teams to minimize disease transmission in response to reports from surveillance systems.

While we believe, like others, that risk assessment and prevention may be the most rewarding direction for international efforts to enhance human security, there are also substantial opportunities in the area of protection. The recent success in the campaign to ban landmines has opened up the prospect of other international agreements to make the weapons of war more focused on combatants, thus reducing the insecurity of noncombatants. International efforts to develop agreements on cluster bombs have a similar motivation. Other strategies for protection include efforts to enhance the quality of buildings in earthquake-prone areas, as well as social mechanisms to protect vulnerable groups during economic crises. Humanitarian disaster response is also a form of protection.

Finally, the international community could enhance efforts at compensation by creating organizations to provide insurance against the financial costs associated with major risks to human security. Most nations effectively self-insure against the costs of major catastrophes. The end result is that many find themselves facing long-term impacts of crises, whether Hurricane Mitch or civil war. Traditional concepts of insurance could perhaps be developed to provide nations at high risk of these events with some financial risk protection.

More detailed implications for policy would, we believe, follow from a structured application of this framework to the challenges of human security. At this point, building the evidence base for human security must be a priority if the focus of international action is to move from reacting to the latest humanitarian crisis to effectively enhance human security through risk assessment, prevention, protection, and compensation.*

\footnotetext{
${ }^{70}$ B. Levy and Victor W. Sidel, War and Public Health (New York: Oxford University Press, 1996).

* For helpful comments and discussions, we thank Jim Alt, Lara Birk, Barry Bloom, Bear Braumoeller, Lincoln Chen, Kristian Gleditsch, Devesh Kapur, Bob Keohane, Lisa Martin, Bruce Russett, Kenji Shibuya, Celeste Wallander, and Langche Zeng.
} 


\section{APPENDIX}

We define individual human security to be $Y I H S_{i}=\int_{0}^{\infty}\left[1-P_{i}(t \mid \tau)\right] S_{i}(t) \delta^{\prime} d t$, where $P(t \mid \square)$ is the probability of individual $i$ being in a state of generalized poverty at time $t$ given a vector of thresholds $\square$ that define generalized poverty in critical domains of well-being, conditional on being alive, and $S(t)$ is the probability that the individual is alive at time $t$ (the so-called survivorship function). Thus, if an individual has an elevated risk of death in the future, manifested by a decrease in $S(t)$, then their individual human security has decreased. The discount factor is $\tau$, which equals one if the prospect of being in a state of generalized poverty in the distant future contributes as much to years of an individual's human insecurity as the prospect of being in generalized poverty in the near future. When $\Delta$ is less than 1 then the prospect of being insecure in the distant future contributes less than in the near future. In addition, $P(t)$ and $S(t)$ are each conditional on the information set available. In the present case, we define the information set as including all data available to at least one person, but not necessarily the person for whom we are calculating YIHS. Individuals who pay a lot of attention, are smart, have sociological imaginations, have access to education and other knowledge, etc. will often be able to do better than a statistical analyst in forecasting, since they condition on more information. Others who are not so fortunate will probably not be able to forecast as well as a statistical analyst. Thus, part of the goal of the international community probably ought to be to equalize the information sets by distributing information about our forecasts.

YIHS is analogous to the familiar period life expectancy measure, a calculation based on mortality rates by age observed for a single period of time, usually a year. Period life expectancy is the average length of life for a hypothetical group of newborns born today who would experience over the course of their life currently observed mortality rates at each age. As such, period life expectancy is a convenient summary measure of current mortality experience, even though it does not pertain to any actual group of individuals. The proposed measure of human security is also based on the concept of a life table with two key modifications. First, human security is by definition about the future and reflects our uncertainty about the future. Individual human security is thus always calculated prospectively. Second, we are applying the concept of life expectancy at the individual level. Period life tables are usually calculated for populations. At the individual level, however, the concept of life expectancy or the area under the individual's survivorship function can be applied prospectively.

To clarify potential differences between YIHS and individual perceived human security (PYIHS), we define the latter formally as, $P Y I H S_{i}=\int_{0}^{\infty}\left[1-P_{l}^{p}\left(t \mid \tau_{i}\right)\right] S_{i}^{p}(t) \delta_{i}^{i}(t) d t$, where $\tau_{i}$ is the vector of thresholds that individual $i$ uses to define for herself a state of generalized poverty. For example, auto workers in Detroit faced with the prospect of unemployment may perceive themselves as insecure because the threshold they use to define deprivation is much higher than the global income poverty threshold. $S_{l}^{p}(t)$ is the subjective survivorship function for individual $i$ and $P_{l}^{p}\left(t \mid \lambda_{i}\right)$ is his or her subjective probability of falling below the generalized poverty threshold. Individuals are well known to overestimate small risks and underestimate large risks, ${ }^{71}$ so that their subjective assessments underestimate their human security in secure environments and overestimate them in risky environments. They also generally have a different information set available to make forecasts than we use to define YIHS. This formulation of PYIHS also includes individuals' discount rate for the future.

PYIHS is based on an individual's forecasts of the probability of being in a state of generalized poverty, as well as on forecasts of survival. This measure of PYIHS is strictly relative to the expectations and subjective probabilities of the individual. In other words, PYIHS could increase (as we all know from real life experience) not because the actual probabilities of generalized

${ }^{71}$ Amos Tversky and Daniel Kahneman, Risk and Rationality: Can Normative and Descriptive Analysis Be Reconciled (College Park, MD: Institute of Philosophy \& Public Policy, 1988). 
poverty or survival have changed but because an individual's subjective assessment of these changes or their discount rate changes.

Because we have chosen to define population human security in terms of forecasted generalized poverty and survivorship does not mean that we think that an individual's own assessments of their human security is unimportant. Clearly, if population human security is high but most individuals perceive that their human security is low, this is a concern for public policy and for the community as a whole. Simply providing the public with better risk assessment may serve to enhance perceived human security if people have overestimated risks of generalized poverty or death. Nevertheless, from the vantage point of development and security, we believe that population human security based on estimated probabilities is of the greatest policy relevance.

IPHS may be based on the high discount rates that many individuals, especially the poor, use in their daily life decisions. We also know that discount rates used for policy decisions, such as investments in water or environmental projects, are typically and reasonably much lower than individual discount rates. ${ }^{72}$ Based on long-standing arguments against discounting future utility, ${ }^{73}$ we believe that a reasonable approach is to evaluate the risks of generalized poverty five years hence as being as important or nearly as important as in ten years.

Finally, we define

$$
\mathrm{IHS}_{1}=\frac{\mathrm{YIHS}_{\mathrm{i}}}{\int_{0}^{\infty} S_{l}^{\prime} \cdot(t) \delta^{t} d t}
$$

where $S_{i}^{\prime}(t)$ is the standard survivorship function for someone with the sex and age of individual i. The denominator is the discounted expected years of life an individual can reasonably aspire to. In this way, if an individual faces an increased risk of death in the future, IHS will decrease.

${ }^{72}$ R. C. Lind, ed., Discounting for the Time and Risk in Energy Policy (Baltimore: John Hopkins University Press, 1982); S. A. Marglin, "The Social Rate of Discount and the Optimal Rate of Investment," Quarterly Journal of Economics 77 (1963): 95-111; A. K. Sen, "Isolation, Assurance and the Social Rate of Discount," Quarterly Journal of Economics 81 (1967): 112-24.

${ }^{73}$ F. P. Ramsey, "A Mathematical Theory of Saving," Economic Journal 38 (1928): 543-559; D. Parfit, Reasons and Persons, (Oxford, UK: Oxford University Press, 1984). 